\title{
Ecotoxicity tests on solid residues from microwave induced pyrolysis of different organic residues: An addendum
}

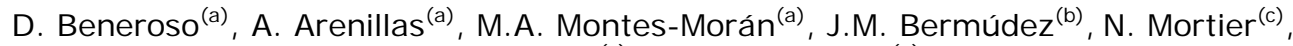 \\ S. Verstichel*(c) ${ }^{\text {, J.A. Menéndez*(a) }}$ \\ (a) Instituto Nacional del Carbón (CSIC), Apartado 73, 33080 Oviedo, Spain \\ (b) Chemical Engineering Department, Imperial College London, SW7 2AZ, London, \\ United Kingdom \\ (c) OWS nv, Dok Noord 5, 9000 Gent, Belgium
}

\begin{abstract}
Microwave-induced pyrolysis of organic wastes has been demonstrated to be a suitable technology for the production of syngas $\left(\mathrm{H}_{2}+\mathrm{CO}\right)$. However, there is a need for developing alternatives to manage the residual streams from this process. In this short communication, the use of the solid fraction from microwave-induced pyrolysis as a soil conditioner and its ecotoxic effect on the growth of barley and cress plants have been studied. The porous structure of these chars has been found out to be one of the possible factors related to the germination rates. This alternative has resulted to be highly promising since the toxic effect on plants germination was very limited or non-existing regardless of the municipal waste char composition.
\end{abstract}

\section{Keywords}

Organic municipal solid waste; Pyrolysis; Biochar; Plant toxicity

\section{I ntroduction}

Pyrolysis of complex residues, such as municipal solid wastes, involves the production of a solid fraction (char) which usually has a low value owing to its high ash content [1-3]. Among the different recycling alternatives, char is typically used as a raw material for fueling $[4,5]$ and the production of adsorbents $[6,7]$. However, ashes lead to a decrease in the calorific value of the chars and carbon concentration, probably being more feasible their use as a soil amendment since they are known to increase soil fertility and cycle nutrients back into agricultural fields [8]. The influence of different pyrolysis parameters on the stability, nutrient availability, salinity, hydrophobicity or $\mathrm{pH}$ of the chars has been studied $[1,9]$. In general, chars from high temperature pyrolysis use to be alkaline, with a more developed porosity and higher amounts of ashes. These characteristics make chars to be useful on excessive acid soils to improve the availability of nutrients or in soils 
with low water retention. Furthermore, high temperature-derived chars have been pointed out to be especially attractive for sequestering carbon, since they contain highly recalcitrant carbon that can stay for years in the soil [1].

During the last years, a series of investigations on the microwave-induced pyrolysis (MIP) of different organic substrates were carried out. Results regarding the influence of operational conditions on the gas and oil fractions were published in Journal of Analytical and Applied Pyrolysis [10,11]. This short communication is an addendum to those works. Herein, the possibility of using the solid residue from the pyrolysis of municipal solid wastes, both dried and wet, and agricultural waste (straw) as an additive to soils is evaluated from a biological standpoint by means of plant toxicity tests.

\section{Experimental procedure}

\subsection{Char preparation}

The biochars were obtained by means of MIP of three different feedstocks:

1. An organic fraction from a municipal solid waste (MSW), obtained from a landfill in Seville (Spain). This fraction was subjected to a size reduction of 1-3 $\mathrm{mm}$. The MSW-derived char is labelled as MSW-Char.

2. An organic fraction from a municipal solid waste, dried and partially cleaned from inerts (MSWd). This fraction was taken from the previous fraction (MSW) and subjected to removal of moisture and inert solids, such as glass or metals. After this pre-treatment, the fraction size was reduced to 1-3 $\mathrm{mm}$. The char produced from this fraction is labelled as MSWd-Char.

3. An agricultural residue. This sample was obtained from a biodiesel production plant located in Salamanca (Spain) and is composed of straw. The sample was also milled to a size range of $1-3 \mathrm{~mm}$. The straw derived char is labelled as STR-Char.

MIP was performed using an unimode microwave oven provided by MES (Microondes Énergie Systèmes) consisting of a microwave magnetron with a maximum output power of $2 \mathrm{~kW}$ operating at $2450 \mathrm{MHz}$ and a single mode cavity where the sample-containing quartz reactor was placed. To ensure an oxygen-free atmosphere, the reactor was purged with $\mathrm{N}_{2}$ for 30 minutes at a flow rate of 50 $\mathrm{mL}_{\text {stp }} \mathrm{min}^{-1}$. Then, the flow rate was reduced to $10 \mathrm{~mL}_{\text {sTP }} \mathrm{min}^{-1}$ and the microwave

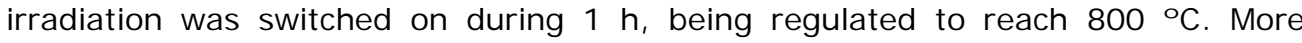
details on the experimental work can be in a previous publication [10]. 
Biochars from MIP were characterized as follows. The moisture, ash and volatile matter content were obtained by means of a LECO TGA-601. To perform the ultimate analysis, a LECO-CHNS-932 micro-analyzer and a LECO-TF-900 furnace were used. The micro-analyzer provides carbon, hydrogen, nitrogen, and sulfur percentage composition. The oxygen content was determined by difference (Table $1)$.

Table 1. Characterization of the feedstock and feedstock-derived chars

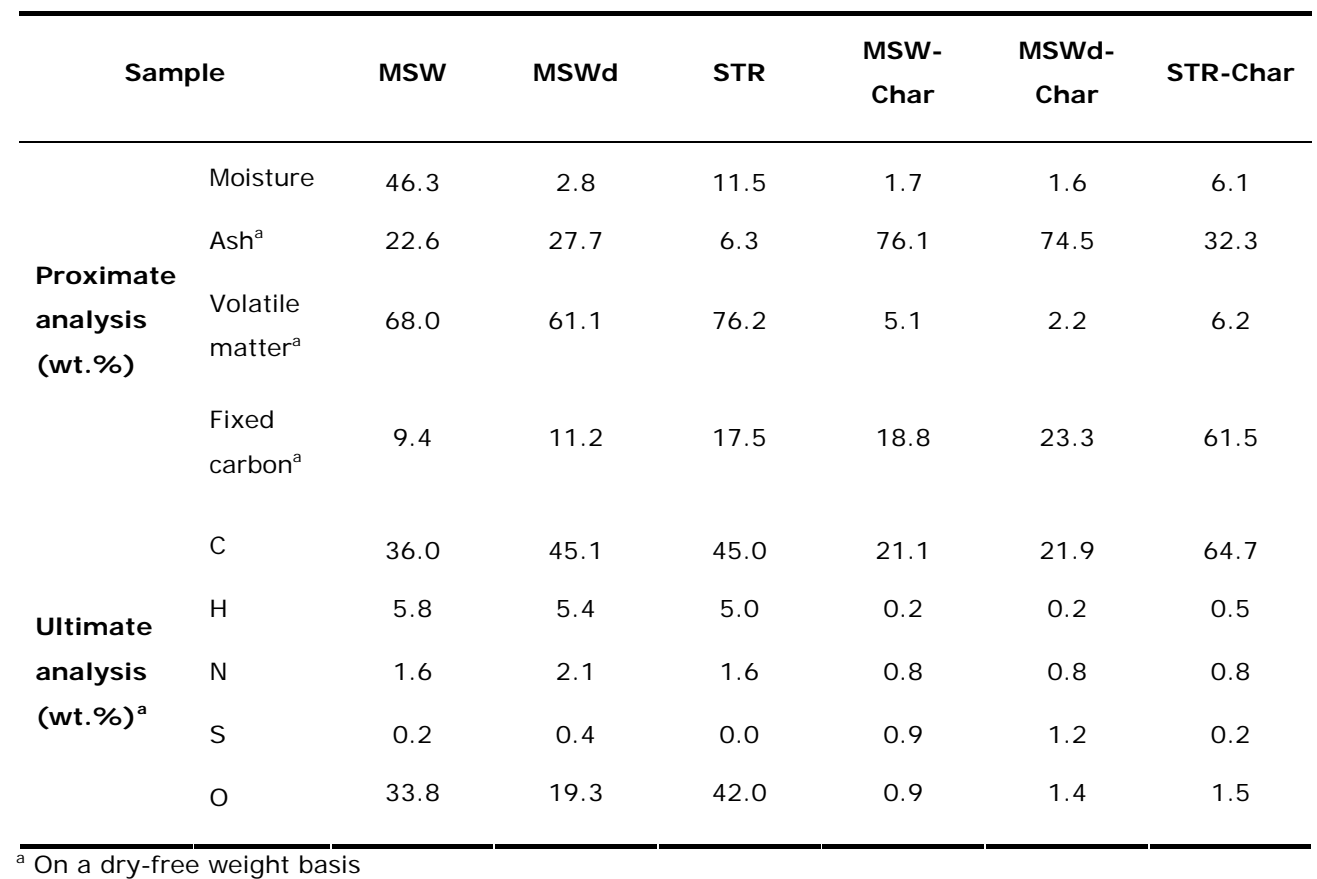

The content of metals from the char was determined by means of atomic absorption spectroscopy using an Agilent 7700x. The results from this characterization are presented in Table 2 along with the limit levels on heavy metals as defined by the European Ecolabel on soil improvers [12].

Table 2. Characterization of the metals from the produced chars

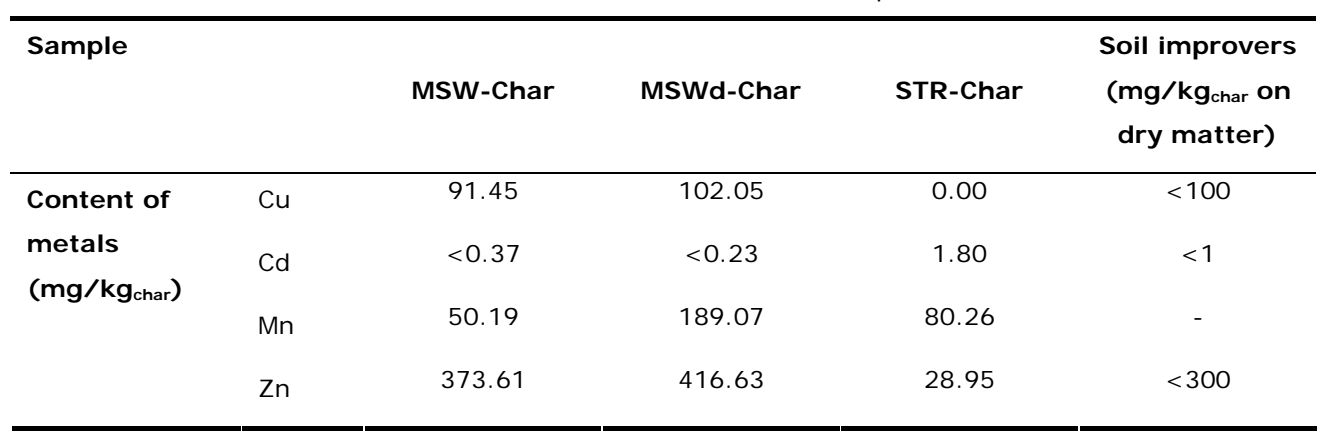




\begin{tabular}{ccccc}
\hline Fe & 18141.64 & 20264.92 & 1258.33 & - \\
$\mathrm{Pb}$ & 63.57 & 70.16 & $<0.44$ & $<100$ \\
$\mathrm{Cr}$ & 118.96 & 133.71 & 0.00 & $<100$ \\
$\mathrm{Ni}$ & 35.69 & 40.09 & $<0.44$ & $<50$ \\
$\mathrm{TI}$ & $<0.37$ & $<0.23$ & 0.00 & - \\
\hline
\end{tabular}

\subsection{Plants growth tests}

The plant tests were executed in line with the OECD Guideline for Testing of Chemicals 208 Terrestrial Plant Test: Seedling Emergence and Seedling Growth Test (2006). The different chars were therefore mixed with natural soil in a $1 \mathrm{wt} \%$ and 3 wt.\% concentration (on wet weight basis) and the germination and growth of two different higher plant species (barley (Hordeum vulgare) and cress (Lepidium sativum)) were evaluated. The compost usage to arable land is in many European countries restricted till 15 ton dry compost $\cdot \mathrm{ha}^{-1} \cdot \mathrm{y}^{-1}$, but in Austria a dosage of 40 ton dry compost $\cdot \mathrm{ha}^{-1} \cdot \mathrm{y}^{-1}$ can be applied for non-food regular application [13]. Taking into account a normal depth of soil tillage of $0.2 \mathrm{~m}$ and a soil density of $1500 \mathrm{~kg} \cdot \mathrm{m}_{\mathrm{a}}^{-3}$, this results in a maximum addition of compost (dry weight) to arable soil of $1.3 \mathrm{wt}$ \%. The $3 \mathrm{wt}$ \% concentration consequently includes a safety factor of 2.3. The tests were performed in triplicate using $180 \mathrm{~g}$ of natural soil to which chars from MSW, MSWd and STR were added in two different concentrations; also the natural soil without addition (blank) was tested. The applied soil was sandy-loam type (clay: $12.0 \%$, silt: $21.2 \%$ and sand $66.8 \%$ ). The soil was a mixture of equal amounts of natural soils collected on three different locations in Belgium (Lokeren and Moerbeke). Before use, the soils were sieved over a $2 \mathrm{~mm}$ screen to remove stones and other inert materials, recognizable roots and other plant debris, and thoroughly mixed. The duration of the tests was 10 days (in the case of barley) and 14 days (in the case of cress) and the relative germination rate (percentage of germinated plants compared to the total number of seeds initially added to the soil), as well as the fresh and dry biomass weight yields (mass of plants produced, fresh and after a drying step, respectively) were evaluated.

\subsection{Porosity determination}

Skeletal and bulk densities were determined by helium (Accupyc II 1340, Micromeritics) and envelope (Geopyc 1360 Envelope Density Analyzer, Micromeritics) pycnometry, respectively. The overall porosity was determined from the bulk and skeletal densities. 


\section{Results and discussion}

The relative germination rate of the two plants in the different amended soils is represented in Figure 1. In general, this parameter remains at a value of ca. $90 \%$ with the exception of STR-Char soils.

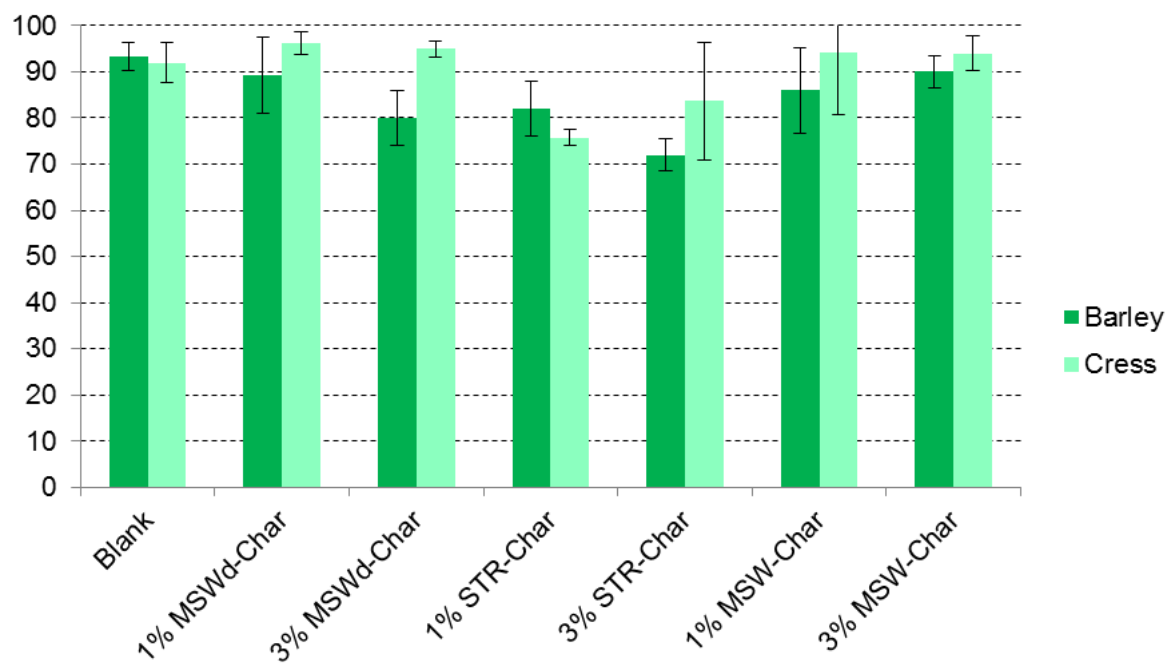

Figure 1. Relative germination rate (\%) of barley and cress using different char types and concentrations

The biomass production yields are shown in Figure 2. Fresh yields are always higher than dry yields due to the amount of accumulated water. In the case of barley plants (Figure 2a), the fresh yields for every char-containing soil are higher than that from the blank soil. The added chars might have positively influenced the water retention capacity, although also other factors as altering soil pH, influencing microbe communities or increasing cation exchange capacity can play a role. Nevertheless, in the case of cress plants (Figure 2b), the biomass yields seem to be not so influenced by the addition of char.
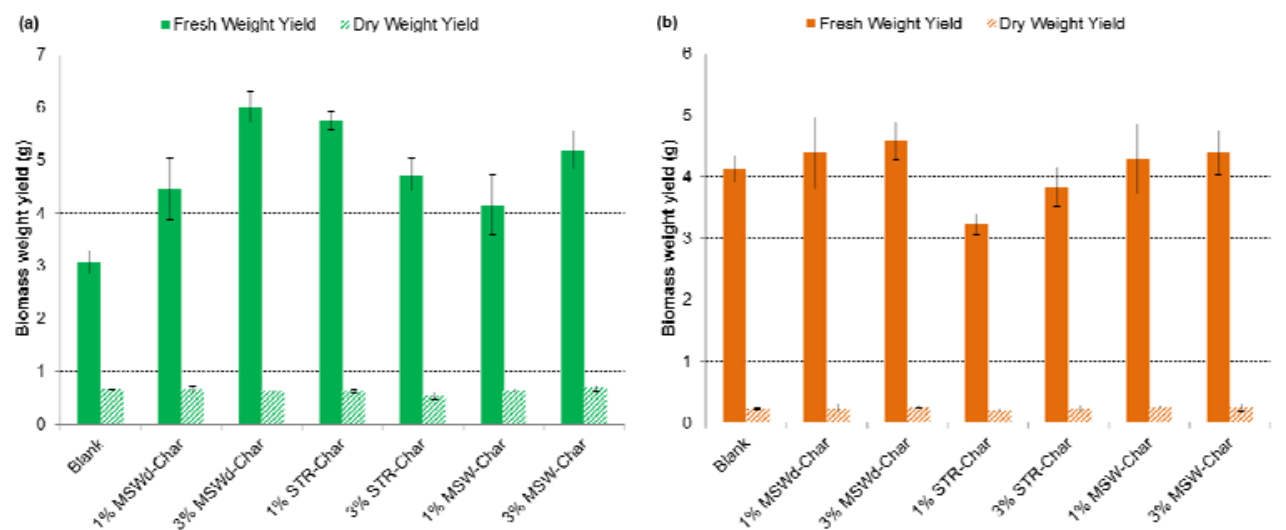
Figure 2. (a) Barley plants and (b) Cress plants yields using different char types and concentrations

The germination rate and the plant biomass of the soil samples to which char was added when compared to the germination rate and the plant biomass of the plants in the natural soil (blank soil) are shown in Figures 3-4. Generally it is considered that a product does not adversely affect plant emergence or growth when the germination and plant yield is at least $90 \%$ of a blank soil to which no test product is added.

In the case of barley plants, the germination rate of the soil samples with $3 \%$ MSWd-Char, 1\% STR-Char and 3\% STR-Char is lower than $90 \%$ of the blank soil, although the reached values are very close to $90 \%$. The biomass yields of the soil samples are generally above $90 \%$ when compared to the blank soil, but not the biomass yield on a dry weight basis of the $3 \%$ STR-Char soil sample. In the case of cress plants tests, the negative effect was even lower; the germination rate and the plant biomass (on fresh weight basis or on dry weight basis) are generally higher than $90 \%$ when compared to the blank soil. Only the soil sample $1 \%$ STR-Char fails the required criteria.

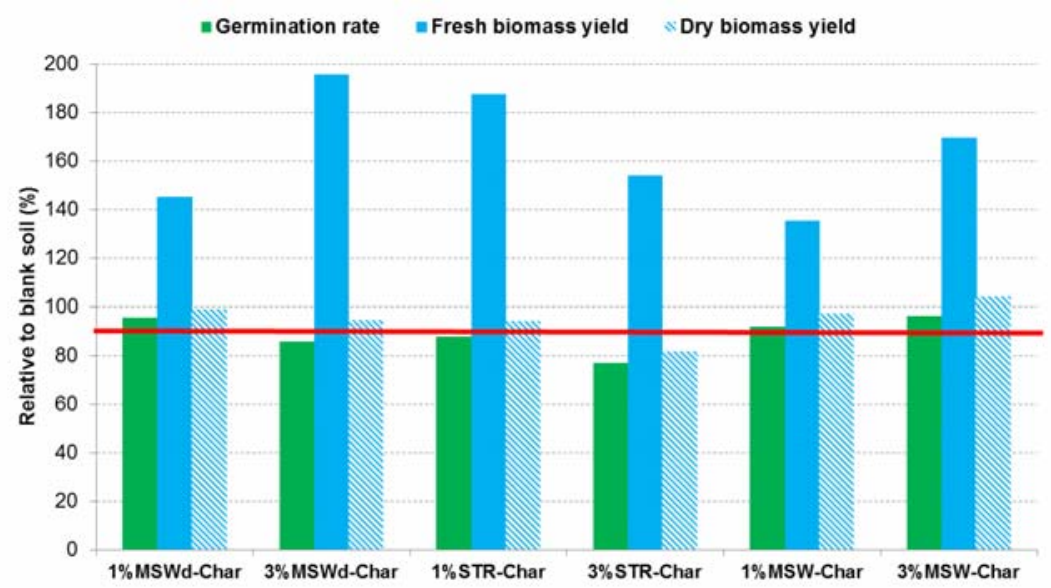

Figure 3. Barley plants passing levels 


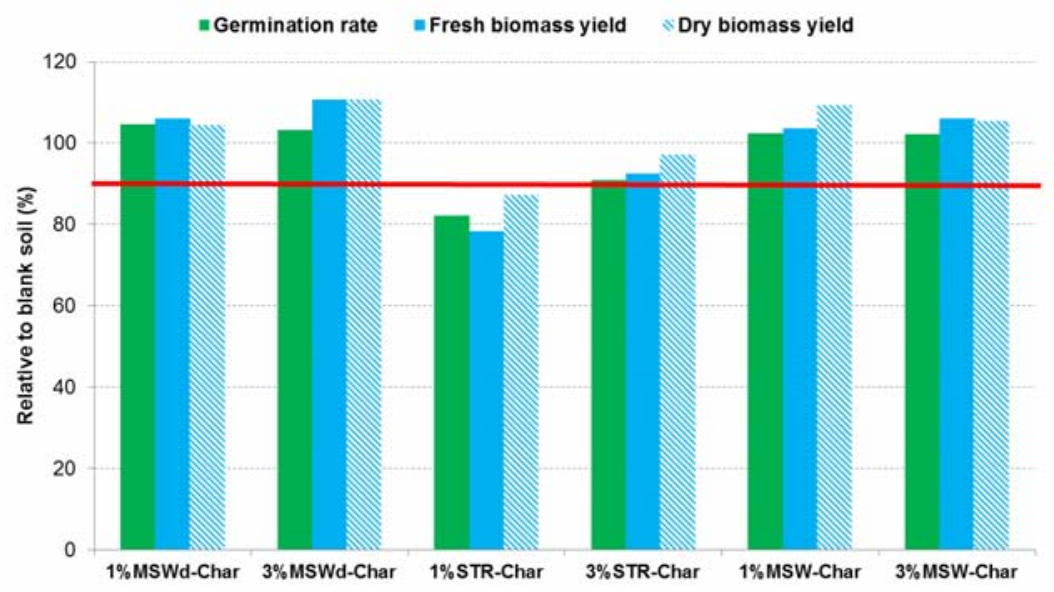

Figure 4. Cress plants passing levels

The differences found within using different chars may be related to their porous structure. The porous structure of biomass-derived chars obtained at high temperature can retain water and improve water balance which makes nutrients more available for the plants [1]. The porosity of the biochars is shown in Table 3.

Table 3. Porosity of the different biochars

\begin{tabular}{cccc}
\hline & MSW-Char & STR-Char & MSWd-Char \\
\hline Bulk density $\left(\mathrm{g} / \mathrm{cm}^{3}\right)$ & 1.26 & 0.83 & 0.58 \\
Porosity $(\%)$ & 48 & 59 & 77 \\
\hline
\end{tabular}

As depicted in Figure 3, the fresh biomass yield from barley plants is always higher as compared to the blank soil (yield relative to blank soil $>100 \%$ ). The effect of porosity may be promoting a better absorption of water from the soil. The same fact is occurring for cress plants, except in the case of using the STR-Char. Furthermore, the differences between barley and cress plants indicate that not only the nature of the char and its porosity is affecting the growth of the plants, but also the type of plant species used, although the dry biomass yield is generally higher when using MSW-Char and MSWd-Char. These results suggest that the char obtained after pyrolysis of municipal solid waste might be added to soil without affecting plant growth negatively.

However, municipal solid waste can be contaminated with heavy metals and therefore, the effect of the ashes composition should also be taken into account regarding to the application of biochars to soil. Although the plants studied are able to grow in the amended soils (sometimes with better germination rates and biomass yields as compared to the blank soil), the content of $\mathrm{Cr}$ and $\mathrm{Pb}$ are 
especially high in the case of MSWd-Char and MSW-Char fractions. These metals are known to be bioaccumulative and, according to the eco-label for soil improvers from the EU, their concentrations must be lower than $100 \mathrm{mg} / \mathrm{kg}_{\text {char }}$ [12]. In our case, the upper limit for $\mathrm{Cr}$ is exceeded in MSW-Char and MSWd-Char (Table 2); the use of these chars being prevented for use as soil improver, at least in soils growing plants for use as food. On the other hand, the Zn content on both MSWChar and MSWd-Char is superior to $300 \mathrm{mg} / \mathrm{kg}_{\text {char }}$ (limit level). Nevertheless, taking into account that the limits are only exceeded to relatively small extents, a careful

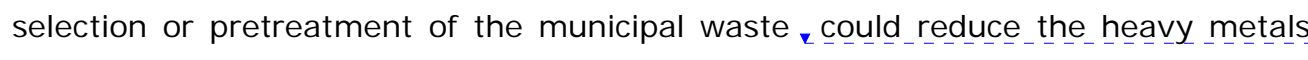
content in a sufficient extent in order to allow the addition of this type of char to soil, even for food production. However, more research on the toxicological effect of char on other soil organisms (e.g. invertebrates and soil micro-organisms) should be performed.

Although even for biochar no distinct agronomic benefits on soil fertility could consistently be demonstrated [14], biochar might be upgraded by adding fertilizers, resulting in an affective soil improver [15-17]. In this way the current char from organic waste sources is no longer a waste product for storage in landfills, but a valuable product for agriculture.

\section{Conclusions}

Generally it can be concluded that the toxic effect of the chars derived from organic wastes and agro-residues on plants was limited or non-existing. Furthermore, the char porosity seems to influence the fresh biomass yield by enhancing the water absorption. Although this research was only limited, the char obtained from municipal solid waste can possibly be added to soil for carbon sequestration without negatively affecting soil fertility. Alternatively the char can be upgraded by addition of fertilizers. However, further research is needed.

\section{Acknowledgements}

The research leading to these results has received funding from the European Union's Seventh Framework Programme for research, technological development and demonstration under grant agreement $\mathrm{n}^{\circ} 311815$ (SYNPOL project). D. B. also acknowledges the financial support received from PCTI and FICYT of the Government of the Principado de Asturias. 


\section{References}

[1] D. Rehrah, R.R. Bansode, O. Hassan and M. Ahmedna, Physico-chemical characterization of biochars from solid municipal waste for use in soil amendment, Journal of Analytical and Applied Pyrolysis (2016).

[2] D. Beneroso, A. Albero-Ortiz, J. Monzó-Cabrera, A. Díaz-Morcillo, A. Arenillas and J.A. Menéndez, Dielectric characterization of biodegradable wastes during pyrolysis, Fuel. 172 (2016) 146-152.

[3] Y. Tang, X. Ma, Z. Lai, H. Lin and J. Wu, Char characteristics of municipal solid waste prepared under N2 and CO2 atmospheres, Journal of Analytical and Applied Pyrolysis. 101 (2013) 193-198.

[4] E. Henrich, S. Bürkle, Z.I. Meza-Renken and S. Rumpel, Combustion and gasification kinetics of pyrolysis chars from waste and biomass, Journal of Analytical and Applied Pyrolysis. 49 (1999) 221-241.

[5] C.R. Lohri, H.M. Rajabu, D.J. Sweeney and C. Zurbrügg, Char fuel production in developing countries - A review of urban biowaste carbonization, Renewable and Sustainable Energy Reviews. 59 (2016) 1514-1530.

[6] P.J. Mitchell, T.S.L. Dalley and R.J. Helleur, Preliminary laboratory production and characterization of biochars from lignocellulosic municipal waste, Journal of Analytical and Applied Pyrolysis. 99 (2013) 71-78.

[7] C.A. Takaya, L.A. Fletcher, S. Singh, K.U. Anyikude and A.B. Ross, Phosphate and ammonium sorption capacity of biochar and hydrochar from different wastes, Chemosphere. 145 (2016) 518-527.

[8] K.Y. Chan, L. Van Zwieten, I. Meszaros, A. Downie and S. Joseph, Agronomic values of greenwaste biochar as a soil amendment, Soil Research. 45 (2007) 629-634.

[9] R. Zornoza, F. Moreno-Barriga, J.A. Acosta, M.A. Muñoz and A. Faz, Stability, nutrient availability and hydrophobicity of biochars derived from manure, crop residues, and municipal solid waste for their use as soil amendments, Chemosphere. 144 (2016) 122130.

[10] D. Beneroso, J.M. Bermúdez, A. Arenillas and J.A. Menéndez, Comparing the composition of the synthesis-gas obtained from the pyrolysis of different organic residues for a potential use in the synthesis of bioplastics, Journal of Analytical and Applied Pyrolysis. 111 (2015) 55-63.

[11] D. Beneroso, J.M. Bermúdez, A. Arenillas, F. de la Peña, J.L. García, M.A. Prieto and J.A. Menéndez, Oil fractions from the pyrolysis of diverse organic wastes: The different effects of conventional and microwave induced pyrolysis, Journal of Analytical and Applied Pyrolysis. 114 (2015) 256-264.

[12] User Manual European Eco-label Soil Improvers (2006).

[13] M. Pollak and E. Favoino, Heavy metals and organic compounds from wastes used as organic fertilizers: Annex 2 Compost quality definition - Legislation and standards (2004).

[14] K.A. Spokas, K.B. Cantrell, J.M. Novak, D.W. Archer, J.A. Ippolito, H.P. Collins, A.A. Boateng, I.M. Lima, M.C. Lamb and A.J. McAloon, Biochar: a synthesis of its agronomic impact beyond carbon sequestration, Journal of environmental quality. 41 (2012) 973989.

[15] S.M. Haefele, Y. Konboon, W. Wongboon, S. Amarante, A.A. Maarifat, E.M. Pfeiffer and C. Knoblauch, Effects and fate of biochar from rice residues in rice-based systems, Field Crops Research. 121 (2011) 430-440.

[16] C. Steiner, W.G. Teixeira, J. Lehmann, T. Nehls, J.L.V. Macêdo, W.E.H. Blum and W. Zech, Long term effects of manure, charcoal and mineral fertilization on crop 
production and fertility on a highly weathered Central Amazonian upland soil, Plant and Soil. 291 (2007) 275-290.

[17] M. Yamato, Y. Okimori, I.F. Wibowo, S. Anshori and M. Ogawa, Effects of the application of charred bark of Acacia mangium on the yield of maize, cowpea and peanut, and soil chemical properties in South Sumatra, Indonesia, Soil Science \& Plant Nutrition. 52 (2006) 489-495. 